\title{
THE EFFECT OF SELF-REGULATED ORIENTED LEARNING ON STUDENTS' ACHIEVEMENT AND PERCEPTIONS IN ENVIRONMENTAL POLLUTION MATERIAL
}

\author{
Sari Fitriyaningsih ${ }^{1}$ \\ Endang Susantini ${ }^{2}$ \\ Yuni Sri Rahayu ${ }^{2}$ \\ ${ }^{1}$ Postgraduate Program, Science Study Program, The State University of Surabaya \\ ${ }^{2}$ Biology Department, Faculty of Science and Mathematics, The State University of Surabaya \\ e-mail: sarifitriyaningsih@yahoo.co.id
}

\begin{abstract}
To achieve the 2013 curriculum aims, which is, to prepare Indonesian people that have the ability to live as individuals and citizens who believe, productive, creative, innovative, effective and able to contribute to society, nation, and world civilization, teachers should educate students to become self-regulated learner. The previous studies found that self-regulated learning not only improves students' learning, but it also improves their perceptions. Therefore, the aims of this research were to implemented a certain SRL's elements on pollution topic. It were also to evaluate the effect of self-regulated oriented learning on students' achievement and students' perception. This research involved 64 experienced students from 2 classes in $7^{\text {th }}$ grade of Junior High School 1 Lamongan. This research was conducted in three phases, that are, the development of research instruments, validation of those instruments, and implementation of those instruments in the classroom. The findings showed that SRL implementation in terms of Lesson Plans and worksheet feasibility is in good categories. It was also affected on the students' perceptions of constructivist learning environments about $82.1 \%$, affected on the students' acquired knowledge results about $72.5 \%$, and affected on the students' process skill results about $76.8 \%$. Due to the results, it can be concluded that implementation of SRL was effective for the learners.
\end{abstract}

Keywords: Self-Regulated learning, students' achievement, students' perception

\section{INTRODUCTION}

Developments in science and technology is felt more rapidly during these decades. To adjust the development of science and technology, the quality of education in Indonesia needs to be improved. One of the government's efforts to improve the quality of education in Indonesia, even it is for elementary school, middle school, and higher education, is constantly working to improve the curriculum. Curriculum 2013 is a competency-based curriculum improvement in Indonesia. The curriculum aims to prepare students to become: (1) a quality human that is able to proactively respond to the challenges and ever-changing times, and (2) welleducated man who is faithful and obedient to God Almighty, noble, healthy, knowledgeable, skilled, creative, independent, and (3) citizens of a democratic and responsible (Ministry of National Education, 2012).

To reach this aim, teachers and schools should educate students to become self-regulated learners. Selfregulated learner can utilise strategies and skills to reflect on their learning, making changes in order to complete tasks and succeed, and most importantly, is a learner who takes responsibility for their own learning (Zimmerman, 1989; Corno, 1993; Boekarts, et.al., 2000). In order to develop this responsibility and learner autonomy, the learning environment should encourage active, authentic learning, collaboration, and problem-solving. As described above, the inquiry classroom utilises specific strategies and skills to enable the learner to become motivated and responsible for their own learning. Referring to the rules of education and culture minister (Permendikbud) No. 65 of 2013 concerning the standard process, the implementation of learning science at Junior High School while maintaining an integrated science lesson by using scientific inquiry (Ministry of National Education, 2013). One of the strategies and skills appropriate to create self-regulated learners, that is selfregulated learning.

Self-regulated learning (SRL) is the degree that individuals are metacognitively, motivationally, and behaviourally active participants in their own learning process (Zimmerman, 2001). To promote SRL in classrooms, teachers must teach students the selfregulated processes that facilitate learning. These elements processes often include: goal setting (Schunk, 2001; Zimmerman, 2004), planning (Schunk, 2001; Pressley \& Woloshyn, 1995), self-motivation (Corno, 1993; Wolters, 2003; Zimmerman, 2004), attention control (Winne, 1995; Harnishferger, 1995; Kuhl, 1985), flexible use of learning strategies (Paris \& Paris, 2001; van de Broek et al., 2001), self-monitoring (Kistner et al., 2010; Zimmerman, 2004), appropriate help-seeking (Butler, 1998; Ryan, et al., 2001), and self-evaluation (Winne \& Hadwin, 1998; Schraw \& Moshman, 1995; Zimmerman, 2004).

Morover, Bird (2009) concluded that SRL is inspired by constructivist perspective, pasticularly social constructivism. Social constructivists see motivation to learn as both intrinsic and extrinsic, that is, students are motivated by successfully working with their peers (extrinsic), and also by their internal drive to understand and promote the learning process. In other words, learners are motivated to take control of their own learning. Butler and Winne (1995) claim that the most effective learners self-regulate their thinking and learning. Zimmerman (1994) reiterates this stating that research overwhelmingly suggests that learning is most effective when learners have some control over what and 
how they learn. Self-regulated learners develop skills that enable them to investigate topics in meaningful ways.

There is one questionnaire that has been developed by Taylor and Fraser (1991), namely Constructivist Learning Environment Survey (CLES), was a questionnaire in accordance with the demands of the social constructivist classroom use SRL oriented. Iverach (2007) stated that the relationship between the construction of quantitative statistics such as student achievement and SRL can be linked to students' perceptions of constructivist learning environment in the classroom by using a questionnaire. One instrument that has been designed to measure the dimensions of constructivist pedagogical is CLES (Taylor \& Fraser, 1991; Taylor, Fraser, \& Fisher, 1997). While this instrument can be used to ascertain the effectiveness of constructivist reforms (Burnet, 2003) it may also be effective for quantifying science classrooms in terms of constructivist dimensions and thus enable valid statistical analyses encompassing students' achievement and and SRL. CLES itself is an instrument used to measure students' perceptions of constructivist learning environment, which consists of five rating scale that named: personal relevance, uncertainty, critical voice, shared control, and student negotiation (Taylor, Fraser, \& Fisher, 1997). CLES scales in accordance with the values of SRL (goal setting, planning, self-monitoring, helpseeking, and self-evaluation) that will appear in the teacher learning. Conformity is what makes SRL and CLES suitable for inclusion in the study.

As such reasons, therefore, this study is established to look deeply about effects of implement the learning device in environmental pollution based on selfregulated learning orientation to students' achievement and perception on constructivist learning environment on curriculum 2013. The results of this study based on two indicators: students' achievement and perceptions. First, students' perceptions will be measured using a questionnaire Constructivist Learning Environment Survey (CLES). Second, students' achievement will be measured using authentic assessment and a paper-andpencil test.

\section{RESEARCH METHOD}

\section{A. Subject of Research}

This research involves two classes of $7^{\text {th }}$ grade that contained of 32 students each class of Junior High School 1 Lamongan year 2014-2015.

\section{B. Research Design}

This research uses Randomized Pretest-Posttest Control Group Design (Fraenkel \& Wallen, 2011: 267268) with the following design:

\begin{tabular}{|llll|}
\hline Treatment group & $R$ & $O_{1} X$ & $O_{2}$ \\
Control group & $R$ & $O_{1} C$ & $O_{2}$ \\
\hline
\end{tabular}

Description:

$\mathrm{R}$ :Random assignment of individual to group

$\mathrm{X}$ :Treatment, namely the implementation of SelfRegulated Learning.

$\mathrm{O}_{1}$ : Pretest includes CLES, acquired knowledge 1, and process skill 1.
$\mathrm{O}_{2}$ : Posttest includes reCLES, acquired knowledge 2, and process skill 2 .

C :Control group.

\section{Procedure of Research}

Procedure of this research consists of four phases: preparation and implementation phase.

Preparation phase. Activities undertaken in the preparation phase is to make the learning material and prepare research instruments that are used in this research.

Implementation phase. Implementation of real teaching using SRL treatment. It was also implement learning activities includes the delivery of learning materials, provision of worksheets, and learning test.

Data analysis phase. Quantitative data on this research exist in the form of students' perception and achievement. The students' perception, paper-and-pencil test, and process skills will be analysed using NormalGain and regression.

Report writing phase. From the results of students' perceptions and achievement during learning using SRL obtained it needs to make a report.

\section{Technique of Data Collecting}

There are some of technique of data collecting in this research, namely observation, questionnaire, and test. Observation is conducted to gather data about enforceability of lesson plan, worksheets and students' presentation skills during implementation of SelfRegulated Learning-oriented. Questionnaire is given to obtain student's perception toward constructivist learning environment (CLES). Test is given to obtain student's achievement, includes acquired knowledge of topic under study that is assessed by paper-and-pencil test and performances consisting of process skills sheet.

\section{E. Technique of Data Analysis}

Data of result of students' perception, paper-andpencil test, and process skill test pre test and post test is done quantitative descriptive analysis use Analysis of Covariance. Analysis of Covariance (ANCOVA) is an extension of ANOVA that provides a way of statistically controlling the (linear) effect of variables one does not want to examine in a study. These extraneous variables are called covariates, or control variables. (Covariates should be measured on an interval or ratio scale). ANCOVA allows you to remove covariates from the list of possible explanations of variance in the dependent variable. ANCOVA does this by using statistical techniques (such as regression to partial out the effects of covariates) rather than direct experimental methods to control extraneous variables. ANCOVA is used in experimental studies when researchers want to remove the effects of some antecedent variable. For example, pretest scores are used as covariates in pretest-posttest experimental designs (Field, 2013).

\section{RESEARCH FINDINGS AND DISCUSSION}

This research is done in implementation phase, but before implementation, researcher develops learning material and the learning material is validated by expert 
of education and expert of environment. In detail, the implementation phase as follows.

\section{A. Result of Self-Regulated Learning Implementation \\ 1. Lesson Plans Implementation}

Observations result of lesson plan on threatment and control class got the mean score ranged between 3-4, it is include include opening, core and closing for three times face to facemeeting. Detail in comparison between these two classes can be briefly presented in Chart 1 below.

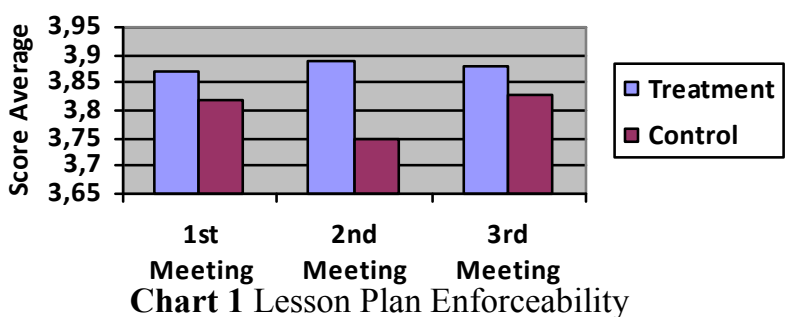

Based on observations enforceability of lesson plans that conducted by two observers on Chart 1 states that all stages on both of class of the learning done entirety with each aspect have well category, which are in the range of 3.0-4.0. But in the treatment class there are shortcomings in the management of time, especially at the last meeting. Lack of time management at the last meeting due to lack of time management when students conduct experiments outside the classroom, that is Environmental Impact of Air Pollution on yard. For other meeting time management goes well.

Based on observations enforceability of lesson plans that conducted by two observers on Chart 1 control class constraints encountered almost throughout the meeting. Due to the method used by teacher only lectures, students become passive in class. Furthermore the implementation of learning conducted in the last hour, so many students less excited and feel sleepy during the learning. This resulted in an average score of enforceability lesson plan on the control class lower than the treatment class. The same thing did not happen in treatment class, because although the implementation of the learning takes place in the last hour, the students in treatment class become active according what is required by the SRL, which is: in Self-Regulated Learning students are metacognitively, motivationally, and behaviourally active of participants in their own learning process (Zimmerman, 2001).

\section{Worksheets Implementation}

To teach SRL to students did not arise by chance but required preparation, including setting up a classroom environment that stimulates children to learn independently (Winnie, 1995). In this learning activity, researchers design activity on worksheets contained with SRL approach. Developed worksheet contains with scientific method combined with SRL steps.

However, the control class was given different worksheets than treatment class. The material used on the both worksheet are same, the difference only in one aspect, that is: in control class, worksheet does not contain SRL's element. The comparison of treatment and control classes in term of process skills that conducted in the worksheet enforceability results in the table above, can be briefly presented in Chart 2 below.

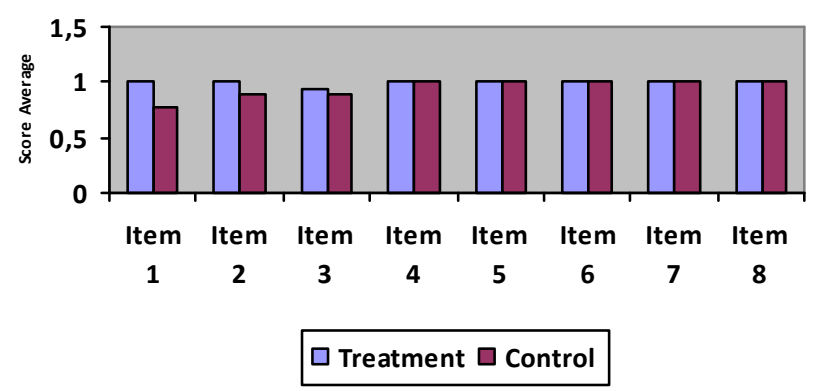

Chart 2 Worksheet Enforceability Result

Based on observation, almost all aspects of worksheet performed by the whole groups. Only a few aspects did not conducted by some groups. It was because they forgot to wrote it down, time constraints in last meeting, and they still did not know what is problem formulation,hypotheses and differences between variables.

In addition to these shortcomings, other aspects of the treatment worksheet get full value, they are: goal setting, chose learning strategy, determine resource, determine time, determine place, formulare research problem, formulate hypothesis, determine equipment and material, plan research prosedure, data record, data analyze, make conclusion and ask questions. These values obtaining because the worksheet instructions are easy to understand and supported by the guidance of the teacher. This is in accordance with the opinion Epstein (2002) explains, they are guided as they approach problems, encouraged to work in groups to think about issues and questions, and supported with encouragement and advice. It is through this guided participation by more skilled adults that children eventually internalize the culturally mediated signs of language and thought termed 'scaffolding' by Vygotsky (1978).

This result is consistent with the statement of Steffens (2006) students who taught by self-regulated learning ranging from setting goals, observing their own learning, make notes about them, evaluate their own performance, can help students learn to change the behavior of self-willingness. When a student faced a problem, so they know when and how to solve problems.

\section{B. Result of Students' Perception on Constructivist Learning Environment}

Students' perceptions of constructivist learning environments are student responses to the social constructivist classroom, where learning is centered on authentic tasks, guided by teacher scaffolding, and engages students in meaningful exploration and inquiry. The students' perceptions were measured using a questionnaire called the Constructivist Learning Environment Survey (CLES). CLES result has different score in treatment and control class. Treatment class using SLR approch get higher score proved by the average of N-Gain CLES achieved a score of 0.66 (medium level) than control class without using SRL approach that is 0.21 (low level). The difference CLES score is not enough to prove the influence of SRL on students' perceptions of constructivist learning 
environment therefore it needs to do a simple linear regression analysis to prove it. The statistical calculation for CLES presented in Table 1 below.

Table 1. SPSS Result for CLES

\begin{tabular}{|l|l|}
\hline \multicolumn{2}{|l|}{ Test of Ancova (Type III Sum of Squares) } \\
\hline Independent variable & Post test of CLES \\
\hline Covariate & Pre test of CLES \\
\hline Treatment & $\begin{array}{l}\text { Approach ("SRL” } \\
\text { or "Non SRL”) }\end{array}$ \\
\hline Significance of Pre_CLES & 0.043 \\
\hline Significance of Approach & 0.000 \\
\hline Significance of Corrected Model & 0.000 \\
\hline $\begin{array}{l}\text { R Square (coefficient of } \\
\text { determination) }\end{array}$ & 0.821 \\
\hline
\end{tabular}

According to Field (2013) in the Type III SS, the process is done without any assumptions based on whether a covariate or treatment that goes into the equation/ model first. So that hypothesis testing is performed twice to determine the linear relationship between the response variable and the covariate to determine the effect of differences in the treatment of category response variable. From the output at Table 4. 7 (page 74) shows that the number of significance for the covariate variables (pre test) is 0.043 , because the value of Sig. $<0.05$ then $\mathrm{H}_{0}$ is rejected. This means that in the $95 \%$ confidence level can be said there is a linear relationship between Pre_CLES with the students' perception of constructivist learning environment (post test). This statement indicates that the assumption of ANCOVA was met. The test is performed by removing the effect of different approach from prior models.

Further testing to determine the effect of different approach to the students' perception of constructivist learning environment (post test). The test is performed by removing the influence of pre test (covariate). From the results it appears that a number of processing variables of significance for approach is 0.000 . Because of its value below 0.05 then $\mathrm{H}_{0}$ is rejected. It can be concluded that without the influence of pre test, in $95 \%$ confidence level there is the effect of SRL tratment on the students' perception of constructivist learning environment (post test). R square's output about 0.821 indicate that there was a significant effect of SRL implementation on score of students' perception on constructivist learning environment (post test) about $82.1 \%$.

The biggest difference contained in scale shared control, uncertainty, and critical voice. It is appropriate with Iverach (2007) that has been tested the compatibility between some elements of SRL and CLES scale. CLES scale in shared control related to goal setting, planning, and self-monitoring on SRL element. According to the theory of SRL in the learning process, students will determine the short-term goals even long-term goals, planning how the learning process will take place, and will periodically monitor their progress. Help-seeking (SRL) associated with the uncertainty in CLES. Regard these two elements are closely related to discussion process. According to SRL theory, students can seek help when encountering difficulties, help-seeking process can be done by discussing among students, even among students and teachers. Last suitability indicated by the self-evaluation (SRL) with a critical voice in CLES. Both of these elements are appropriate, when students know or evaluate learning difficulties. The differences are possible because in the control class, students are not oriented on authentic problems and learning without any elements of SRL.

Other scale that increase is Personal Relevance. It is because learning begin with real world problems that face by students in their every day life. This is the reason why the pollution is very good material for this study because these materials bring the real problems faced by society to be more contextual for a student in a classroom. It is inline with Donovan et al. (1999) state that Self-Regulated learner develop skills that enable them investigate topics in meaningful ways, such as authentic task and inquiry.

\section{Result of Students' Achievement \\ 1. Cognitive Knowledge (Paper-and-Pencil Test)}

The tests were administered to measure cognitive knowledge is in the form of a paper-and-pencil test descriptions. This test involves students' think ability that involves C3-C6 cognitive domains based on the revised Blooms taxonomy.

The increased in pre test and post test in treatment class indicated by the acquisition of $\mathrm{N}-$ Gain value by an average of 0.70 . This value indicates that there is high increase in the students' acquired knowledge. This increase in treatment class is the effect of a given treatment. It was consistent with the measurement of the sensitivity index of each question item, which shows that the index of the sensitivity of the question developed on average of 0.342 . This suggests that the items were to have sufficient sensitivity to the effects of learning are given. This suggests that increased knowledge of cognitive knowledge outcome after a given treatment is given the effect of SRL.

Whereas, the increase in pre test and post test on the control class indicated by the N-Gain grades average at 0.23 . This value indicates that there is low increase in the students' acquired knowledge. This increase is not an effect of learning is given, because the average results of acquisition of each item of sensitivity index of 0.12 . It indicates that the item does not have sufficient sensitivity to the effects of learning was given. This means that the application of learning without SRL approach does not affect the acquisition of students' acquired knowledge.

The results of this assessment in accordance with the research that has been conducted by several researchers such as Wolters (2003), Zimmerman (1989), Schunk (2005), and Camahalan (2009) considers SRL as a series of social cognitive processes associated with positive achieving learning outcomes.

To find that an increase in students 'acquired knowledge is a form of SRL influence on students' concepts mastery, the test results of this study also analyzed using regression analysis. In this following Table 2 was presented SPSS result for Paper-and-Pencil Test. 
Table 2. SPSS Result for Paper-and-Pencil Test

\begin{tabular}{ll}
\hline Test of Ancova (Type III Sum of Squares) \\
\hline $\begin{array}{l}\text { Independent variable } \\
\text { Covariate }\end{array}$ & $\begin{array}{l}\text { Post of Paper-and-Pencil Test } \\
\text { Pre of Paper-and-Pencil Test } \\
\text { Approach ("SRL" or "Non } \\
\text { SRL") }\end{array}$ \\
$\begin{array}{l}\text { Significance of Pre_Paper- } \\
\text { and-Pencil }\end{array}$ & 0.000 \\
$\begin{array}{l}\text { Significance of Approach } \\
\text { Significance of Corrected }\end{array}$ & 0.000 \\
$\begin{array}{l}\text { Model } \\
\text { R Square (coefficient of } \\
\text { determination) }\end{array}$ & 0.000 \\
\hline
\end{tabular}

According to Field (2013) in the Type III SS, the process is done without any assumptions based on whether a covariate or treatment that goes into the equation/ model first. So that hypothesis testing is performed twice to determine the linear relationship between the response variable and the covariate to determine the effect of differences in the treatment of category response variable. From the output at Table 4. 9 (page 77) shows that the number of significance for the covariate variables (pre test) is 0.000 , because the value of Sig. $<0.05$ then $\mathrm{H}_{0}$ is rejected. This means that in the $95 \%$ confidence level can be said there is a linear relationship between Pre Paper-and-Pencil with the students' acquired knowledge (post of Paper-and-Pencil Test). This statement indicates that the assumption of ANCOVA was met. The test is performed by removing the effect of different Approach from prior models.

Further testing to determine the effect of different Approach to the students' acquired knowledge (post of Paper-and-Pencil Test). The test is performed by removing the influence of pre test (covariate). From the results it appears that a number of processing variables of significance for Approach is 0.000 . Because of its value below 0.05 then $\mathrm{H}_{0}$ is rejected. It can be concluded that without the influence of pre test, in $95 \%$ confidence level there is the effect of SRL tratment on the students' acquired knowledge (post of Paper-and-Pencil Test). R square's output about 0.725 indicate that there was a significant effect of SRL implementation on score of students' perception on constructivist learning environment (post test) about $72.5 \%$.

\section{Performance \\ a. Process Skills}

Process skills performed by using the inquiry process is starting with formulated the problem, formulated a hypothesis, determined tools and materials, defined variables, determined the experimental step, recorded the results, and made a conclusions. Treatment class using SLR approch get higher process skills score about 0.68 in medium level, it means that most of students has improve their process skill during SRL implementation. In contras with control class that has $\mathrm{N}$ Gain average about 0.29 that means there are low improvement of process skill in control class.

To know that answer students gave is a form of SRL influence on students' process skill, the test results of this study also analyzed using regression analysis. The statistical calculation for process skills presented in Table 3 below.
Table 3. SPSS Result for Process Skills

\begin{tabular}{ll}
\hline \multicolumn{2}{l}{ Test of Ancova (Type III Sum of Squares) } \\
\hline Independent variable & $\begin{array}{l}\text { Post test of Process } \\
\text { Skill }\end{array}$ \\
Covariate & $\begin{array}{l}\text { Post test of Process } \\
\text { Skill }\end{array}$ \\
Treatment & $\begin{array}{l}\text { Approach ("SRL" or } \\
\text { "Non SRL") }\end{array}$ \\
Significance of Pre_ProcessSkill & 0.000 \\
Significance of Approach & 0.000 \\
Significance of Corrected Model & 0.000 \\
R Square (coefficient of & 0.768 \\
determination) &
\end{tabular}

According to Field (2013) in the Type III SS, the process is done without any assumptions based on whether a covariate or treatment that goes into the equation/ model first. So that hypothesis testing is performed twice to determine the linear relationship between the response variable and the covariate to determine the effect of differences in the treatment of category response variable. From the output at Table 4. 12 (page 80) shows that the number of significance for the covariate variables (pre test) is 0.000 , because the value of Sig. $<0.05$ then $\mathrm{H}_{0}$ is rejected. This means that in the $95 \%$ confidence level can be said there is a linear relationship between Pre_ProcessSkill with the students' process skill (post test of Process Skill). This statement indicates that the assumption of ANCOVA was met. The test is performed by removing the effect of different Approach from prior models.

Further testing to determine the effect of different Approach to the students' process skill (post test of Process Skill). The test is performed by removing the influence of pre test (covariate). From the results it appears that a number of processing variables of significance for Approach is 0.000 . Because of its value below 0.05 then $\mathrm{H}_{0}$ is rejected. It can be concluded that without the influence of pre test, in $95 \%$ confidence level there is the effect of SRL tratment on the students' process skill (post test of Process Skill). R square's output about 0.768 indicate that there was a significant effect of SRL implementation on score of students' perception on constructivist learning environment (post test) about $76.8 \%$.

This is in accordance with what is stated Cheng (2011) that one of the most important aims of education ir to promote students' ability in learning to learn. In order to achieve this aim, teachers need to teach students both knowledge and skill. In the process of self-regulated learning, learning requires that students processess some specific skills, such as set their learning goals, make their learning plans, choose their learning strategies, monitor their learning processes, evaluate their learning outcomes and suppress interference (Boekaerts, Pintrich \& Zeidner, 2000).

\section{b. Presentation Skills}

Presentation skill result used to know students' action which is a coherency between knowledge, skills and how to communicate with other students in front of classroom to deliver the results of experiments that have been done. Presentation of the results of two compare 
class get very good results with range score 3-4 from two observers. Pesentation skills result can be shown in Chart 3 below.

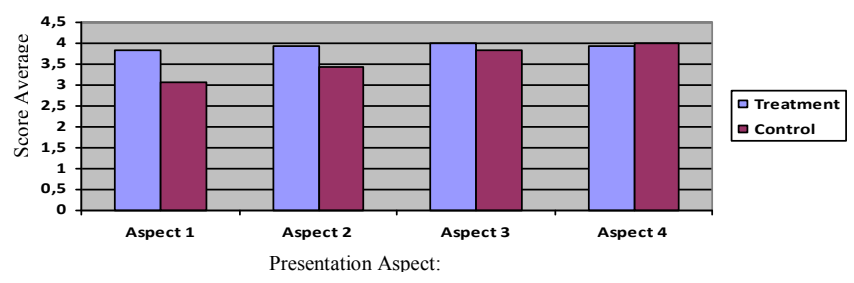

Chart 3. Presentation Skill Result

Treatment class on this aspect getting a mean score of 3.83 and the mean score in control class is 3.08, meaning that students presentate a complete explanation of the key concepts and theories. The second aspect is ability of answering the question, This aspect measures the truth of students' concept in answering questions. In this aspect treatment class getting mean score of 3.92 and a control class is 3.42 , meaning that students can answer the question with deep elaboration. The third aspect is presentation's organization, this aspect measures the order of the material presentation. In this aspect treatment class getting mean score of 4.00 and a control class is 3.83, means presentation is well organized so that audiences can follow easily. The last aspect is group cohesiveness during presentation, this aspect of assessing the cohesiveness of the group when presenting the material. In this aspect treatment class getting mean score of 3.92 and a control class is 4.00, means there is a clear role and every member has balance responsibility in presentation. Although in reality there is one student from group 1, which is passive during the presentation. Finally, based on the rule of education and culture minister (Permendikbud) No. 81A of 2013 concerning affective assessment said that classical assessment of presentation skill in this research is very good.

In addition to having a very good value, presentation action also result students' work, in the form of charts experimental results in the form of posters and power point. Poster produced from second meeting that shows the experimental design and results of water purification. While the students made a power point to present their observations compost for 3 days.

These results are consistent with the Jhonson (2002) statement, on SRL students produce a result, tangible or intangible, that holds meaning for them. There are myriad ways to display the result of self-regulated learning tasks. Most obviously, a group may produce a portfolio, give a presentation using graphs and overheads, perform for an audience, or display and comment on something they have created. The result satisfies a definite purpose that holds meaning in the context of each student's experience, and usually in the conteext of the student's family, school, team, or community.

\section{CONCLUSION}

\section{A. Conclusion}

Based on the explanation above, it could be concluded that well implementation of Self-Regulated Learning approach in classroom got positive effect on students' achievement in term of acquired knowledge and performance, it was also got positive effect on student perceptions in constructivist learning environment.

\section{B. Suggestion}

For supporting the findings of this research, the next study is necessary to consider the learning time because the learning activities based on SRL cannot be carried out during unrealistic time constraint.

\section{REFERENCES}

Bird, L. (2009). Developing self-regulated learning skills in young students. Unpublished Thesis, Deakin University, New Zerland.

Boekaerts, M., Pintrich, P. R., \& Zeidner, M. (2000). Handbook of self-regulation. California: Academic Press.

Burnet, T. C. (2003). The impact of a new science syllabus on developing constructivist classroom learning environments. Unpublished ScEdD Thesis, Curtin University of Technology, Australia.

Butler, R. (1998). Determinants of help seeking: Relations between perceived reasons for classroom help-avoidance and help-seeking behaviors in an experimental context. Journal of Educational Psychology, 90, 630-643.

Butler, D., \& Winne, P. (1995). Feedback and selfregulated learning: A theoretical synthesis, Review of Educational Research, vol. 65, issue 3, 245-281.

Camahalan, F.M., (2006). Effects of self-regulated learning on mathematics achievement of selected Southeast Asian children, Journal of Instructional Psychology, vol.32, issue 3, 194-205.

Cheng, E. C. K. (2011). 'The role of self-regulated learning in enhancing learning performance', The International Journal of Research and Review, vol. 6 (1), 1-16.

Corno, L. (1993). The Best-laid plans: Modern conceptions of volition and educational research. Educational Researcher, 22, 14-22.

Donovan, S., Bransford, J., \& Pellegrino, J. (1999). How people learn: Bridging research and practice. National Academy of Sciences, retrieved 19 January 2014, (http://bob.nap.edu/html/howpeople2/.).

Epstein, M. (2002). Constructivism. Research paper, retrieved 19 January 2014, (http://tiger.towson.edu/ mepste1/researchpaper.ht ml.).

Fraenkel, J. R., Wallen, N. E., Hyun, H. H. (2011). How to design and evaluate research in education (8th ed.). New York: McGraw-Hill.

Hake, R.R. (1999). Analyzing change/gain scores. USA: Indiana University.

Harnishferger, K. K. (1995). The development of cognitive inhibition: Theories, definitions, research. In F. N. Dempster \& C. J. Brainerd (Eds.), Interference and Inhibition in Cognition (pp. 176206). San Diego: Academic Press.

Kistner, S., Rakoczy, K., \& Otto, B. (2010). Promotion of self-regulated learning in classrooms: Investigating frequency, quality, and consequences for student 
performance.

Kuhl, J. (1985) Volitional mediators of cognitionbehavior consistency: self-regulatory processes and action versus state orientation. In J. Kuhl and J. Beckman (eds) Action Control: From Cognition to Behavior (pp. 101-128). New York: Springer.

Ministry of National Education (2012). Curriculum 2013 documens. Jakarta: MONE.

Ministry of National Education (2013). Regulation of education and culture minister number 65 of 2013 concerning standard process for lower secondary level school. Jakarta: MONE.

Paris, S. G., \& Paris, A. H. (2001). Classroom applications of research on self-regulated learning. Educational Psychologist, 36, 89-91.

Ryan, A. M., Pintrich, P. R., \& Midgley, C. (2001). Avoding seeking help in the classroom: Who and why? Educational Psychology Review, 13, 93-114.

Schraw, G., Moshman, D. (1995). Metacognitive theories. Educational Psychology Review, 7, 351371.

Schunk, D. H. (2001). Social cognitive theory and selfregulated learning. In Zimmerman, B. J., \& Schunk, D. H. (Eds.) Self-regulated Learning and Academic Achievement: Theoretical Perspectives. Mahwah, NJ. Lawrence Erlbaum Associates.

Steffens, K. (2006). Self-Regulated learning in technology-enhanced learning environments: Lessons of a European peer review. European Journal of Education, 41(3/4), 353.

Taylor, P.C., Fraser, B.J. (1991). CLES: An instrument for assessing constructivist learning environments.

regulation of learning and performance: Issues and educational applications, Erlbaum, Hillsdale, New Jersey, pp. 3-21.

Zimmerman, B.J. (2001). Theories of self-regulated learning and academic achievement: An overview and analysis. In B. J. Zimmerman \& D. H. Schunk
(Eds.), Self-regulated Learning and Academic Achievement : Theoretical Perspectives (2nd ed., pp. x, 322). Mahwah, NJ: Lawrence Erlbaum Associates.

Zimmerman, B. J. (2004). Sociocultural influence and students' development of academic self-regulation: A social-cognitive perspective. In D. M. McInerney \& S. Van Etten (Eds.), Big theories revisted (pp.139-164). Greenwhich, CT: Information Age.

Paper presented at the Annual Meeting of the National Association for Research in Science Teaching (NARST), The Abbey, Fontaine, Wisconsin.

Taylor, P. C., Fraser, B. J., \& Fisher, D. L. (1997). Monitoring constructivist classroom learning environments. International Journal of Educational Research , 27, 293-302.

van den Broek, P., Lorch, R., Linderholm, T., \& Gustafson, M. (2001). The effects of readers' goals on inference generation and memory for texts. Memory \& Cognition, 29, 1081-1087.

Vygotsky, L. S. (1978). Mind in society. Cambridge, MA: Harvard University Press.

Winne, P. H. (1995). Inherent details in self-regulated learning. Educational Psychologist, 30, 173-188.

Winne, P. H., \& Hadwin, A. F. (1998) Studying as selfregulated learning. In D. J. Hacker \& J. Dunlosky (Eds.), Metacognition in Educational Theory and Practice, The Educational Psychology Series. Mahwah, NJ: Erlbaum.

Wolters, C.A. (2011). Regulation of motivation: Contextual and social aspects. Teachers College Record, 113(2), 265-283.

Zimmerman, B.J. (1989). 'A social cognitive view of self-regulated academic learning', Journal of Educational Psychology, vol. 81, pp. 329-339.

Zimmerman, B.J. (1994). 'Dimensions of academic selfregulation: a conceptual framework for education', in DH Schunk \& BJ Zimmerman (eds), Self- 